medicines, their motives are met with a healthy dose of skepticism from some quarters. An Oxfam report released in November 2007, titled 'Investing for Life', concluded that companies are more interested in setting up these programs to boost their reputations than in establishing tiered-pricing systems, which could serve as a more sustainable way to make medications affordable to all who need them.

"[The companies] decide whom to give it to, for how long and at what price," adds Beverley Snell, an essential drugs specialist at the Macfarlane Burnet Institute for Medical Research and Public Health in Melbourne, Australia. "There are always conditions, limitations, et cetera." Snell notes that medications, to help survivors. by the tsunami in December 2004. ivermectin, for example, is useful against other crippling parasitic diseases such as strongyloidiasis, ascariasis, trichuriasis and enterobiasis. But Merck donates the drug only for river blindness.

According to some experts, it's unrealistic to expect companies to be philanthropic at the expense of their bottom line: "It's a misunderstanding that companies exist to provide drugs," says Nathan. "In fact they exist to make money for their shareholders."

Nathan says it is instead up to individual governments to create a 'medicine fund' that would provide incentives for companies to make certain drugs. A 2002 study from Médecins Sans Frontières (Doctors without Borders) found that of 1,393 new drugs marketed between 1975 and 1999, only 13 were for tropical diseases (Lancet 359, 2188-2194; 2002). But as incentives appear-such as a $\$ 19$ million cash influx from the Bill \& Melinda Gates Foundation to find a drug for sleeping sickness-companies are returning to research on these diseases.

For their part, the companies have their own complaints about the way in which many countries operate. They note, for example, that African nations each have their own complex rules for drug importation and don't make special allowances, such as waiving customs duties, for donation programs. "It's problematic when you're trying to get the product in, and you wind up paying a huge amount of money

\title{
Donation after disaster strikes
}

When a massive cyclone struck Myanmar on 2 May, the World Health Organization (WHO), as it usually does, asked people not to send inappropriate drug donations, such as expired

In the past, however, those pleas have fallen on deaf ears. For example, Aceh, Indonesia, was among the regions worst affected

In the weeks after the tsunami struck, 39 foreign governments and 48 international organizations - many of which had collected drugs from private individuals - together donated more than 4,000 tons of unsolicited drugs to the eight districts in Aceh,

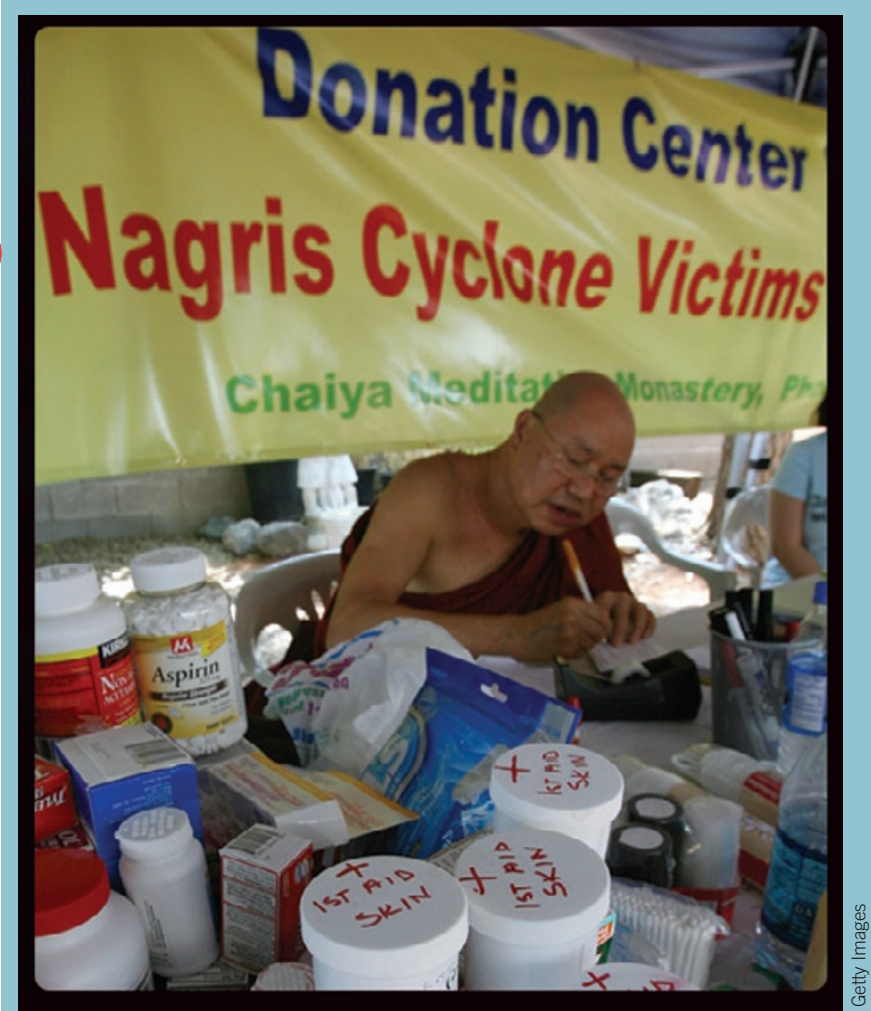

Weathering the storm: Some donations do more damage than good according to a 2005 survey conducted by Pharmaciens Sans Frontières Comité International (Pharmacists without Borders, also known as PSFCl; see <www.psf.ch/de/pdf/synth_inap_ donations.pdf $>$ for full report).

Most of these medical donations made little sense: "There were ridiculous stories of people sending prosthetic hips and winter coats," says Ken Gustavsen, Merck's director for donation programs based in Whitehouse Station, New Jersey. "There were calls on people to open up their medicine cabinets. We were saying, 'No, no, don't do that. That's exactly what you shouldn't do."

About $70 \%$ of the drugs were labeled in languages incomprehensible to residents, and $25 \%$ of the drugs had either already expired or were due to expire in fewer than six months. In nearby Sri Lanka, the government and independent scientists estimated that more than half of drug donations received did not list expiration dates. Other disaster-struck countries have received amphetamine-based appetite suppressants, lip balm, hemorrhoid cream and breast implants.

At best, such donations are a waste, say experts. At worst, they put local residents at risk, or they force governments to dispose of the drugs at great cost.

For example, between 1992 and 1996, the war-torn region of Bosnia-Herzegovina received about 19,000 tons of inappropriate drug donations, which had to be disposed of at a cost of $\$ 34$ million. The high cost reflects that the fact that inappropriate drug donations must be disposed of carefully because they often contain strong, potentially dangerous chemicals.

In 1996, the WHO and other international humanitarian agencies together came up with drug donation guidelines, spelling out that such donations should be made only when the recipient country has expressly asked for them, have a shelf life of at least one year and be clearly labeled.

Most pharmaceutical companies comply with these guidelines. However, as the disaster in Aceh showed, some organizations continue to send in misguided donations. According to the authors of the PSFCI 2005 survey, even after the publication of the guidelines "the quality of humanitarian aid with respect to drug donations in acute emergency situations has not improved."- $A M$ 